جامعـة نيويورك أبـوظـبي $\stackrel{\uplus}{i}$ NYU $\mid$ ABU DHABI

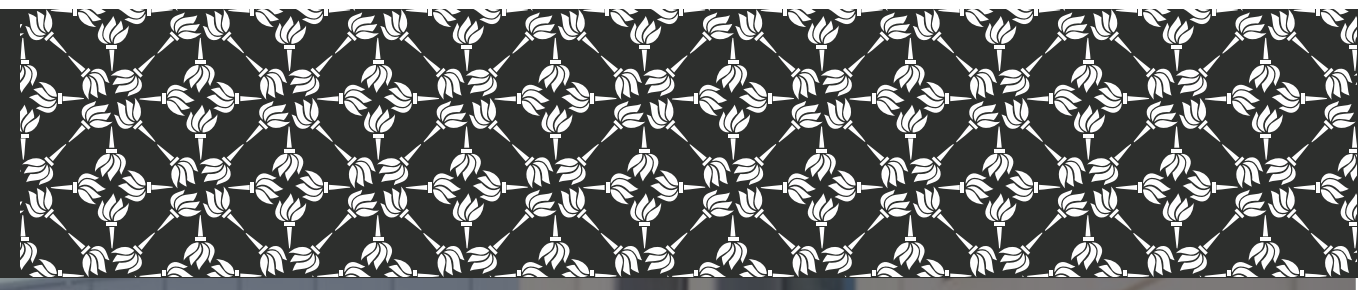

\title{
Measuring preferences for competition with experimentally-validated survey questions
}

Francesco Fallucchi, Daniele Nosenzo, Ernesto Reuben

Working Paper \# 0034

December 2019 


\title{
Measuring preferences for competition with experimentally-validated survey questions
}

\author{
Francesco Fallucchi \\ Luxembourg Institute of Socio-Economic Research (LISER), \\ e-mail: francesco.fallucchi@liser.lu \\ Daniele Nosenzo \\ Luxembourg Institute of Socio-Economic Research (LISER) and University of Nottingham, \\ e-mail: Daniele.Nosenzo@liser.lu; Daniele.Nosenzo@nottingham.ac.uk \\ Ernesto Reuben \\ New York University Abu Dhabi, \\ e-mail: ereuben@nyu.edu
}

\begin{abstract}
We validate experimentally a new survey item to measure the preference for competition. The item, which measures participants' agreement with the statement "Competition brings the best out of me", predicts individuals' willingness to compete in the laboratory after controlling for their ability, beliefs, and risk attitude (Niederle and Vesterlund, 2007). We further validate the explanatory power of our survey item outside of the laboratory, by comparing responses across two samples with predicted differences in their preference for competition: professional athletes and non-athletes. As predicted, we find that athletes score higher on the item than non-athletes.
\end{abstract}

This version: December 2019

JEL Codes: C91, D90, D91

Keywords: competition, survey question, experiment validation

Acknowledgments: We thank Georgia Michailidou for her inputs in the early stages of the project. We are grateful to Sabrina Bravaccini, Dimitri Dubois, and Marc Willinger for their collaboration in collecting the data on professional athletes. We also thank conference participants at the European Meeting of the Economic Science Association in Dijon and the conference "Contests: Theory and Evidence" at the UEA for helpful comments. 


\section{Introduction}

In recent years, economists have grown increasingly interested in non-cognitive factors to explain economic behavior. Heckman et al. (2019) review the economics literature and conclude that factors such as personality traits and preferences, can explain and predict important life outcomes across a variety of social and economic domains, including labor market outcomes and health. If non-cognitive factors are an important source of behavior, it is essential to develop precise empirical tools to measure them accurately. Among such tools, economics experiments offer a number of clear advantages, since they allow the measurement of preferences and traits in an incentive-compatible way and controlling for the influence of confounding factors (Roth, 1995; Erkut and Reuben, 2019). One limitation of this approach, however, is that incentivized experiments may be less practical when conducting large-scale field studies with non-convenience samples (e.g., with members of the general population). In these studies incentivization is not always feasible (e.g., due to difficulties in paying participants, because it would prohibitively expensive), interaction between participants may not be easily organized, and there might be too little time to go through a lengthy experiment. For this reason, experimental and behavioral economists have started developing more portable tools that can be deployed quickly in field settings without incentives, while at the same time retaining the predictive power of incentive-compatible experimental measurements (e.g., Dohmen et al., 2011; Falk et al., 2018). The aim of this paper is to develop one such tool, designed to measure individuals' preference for competition.

Preferences for competition have recently attracted substantial interest among economists. Studies have shown that laboratory measures of these preferences can explain important educational choices and labor market outcomes (e.g., Buser et al., 2014; Berge et al., 2015; Buser et al., 2017a,b; Reuben et al., 2017; Kamas and Preston, 2018; Reuben et al., 2019; Zhang, 2019). The preference for competition is measured through the experimental paradigm introduced by Niederle and Vesterlund (2007). Since this paradigm, which consists of a sequence of interconnected tasks, may be difficult to implement outside of the laboratory, in this paper we develop a more flexible, experimentally-validated survey question to measure preferences for competition in settings that do not allow the high degree of implementation control of the lab.

Our approach to developing a survey item that captures preferences for competition is twofold. First, we follow the methodology introduced by Falk et al. (2016) and Falk et al. (2018) to select and validate our question with observed behavior. We start with a list of eight candidate questions designed to capture either direct or indirect aspects of an individuals' preference for competition. We administer these questions in a survey that participants completed online about two weeks before taking part in a laboratory experiment. In the laboratory experiment, we use a variation of the paradigm of Niederle and Vesterlund (2007) to measure the participants' 
preference for competition in an incentive-compatible way. We then run an econometric horserace between our eight survey questions to identify the question that best explains behavior in the laboratory experiment. This exercise reveals that the survey item that best predicts the participants' preference component of their willingness to perform in a competitive environment is the statement: "Competition brings the best out of me" as an answer to a question asking participants to indicate the extent to which the statement describes them (answers ranged from "Not at all like me" to "Exactly like me").

In a second step, we corroborate the validity of our question by performing an additional validation exercise. This exercise consists in testing whether our question can predict behavior observed outside of the lab. We take an individual's decision to practice sports at a professional level as an indication of the person's preference for competition (Barron et al., 2000). We administer our survey question, under identical experimental conditions, to a group of professional athletes aged 18-30 and to a group of students, who do not practice sports professionally but are of comparable age. We corroborate the predictive power of our question by showing that professional athletes' agreement with the statement "Competition brings the best out of me" is much higher than among non-athletes.

This paper is related to work in social psychology on developing psychometric scales to capture the taste for competition (e.g., Smither and Houston, 1992; Newby and Klein, 2014). Our approach offers a number of advantages relative to these scales. First, our approach offers higher portability: the psychometric scales developed in the social psychology literature typically consist of multiple interrelated questionnaire items that cannot be deployed individually and therefore require considerable time to be administered. In contrast, we aim to develop a single question that can broadly capture people's preference for competition to facilitate its implementation in surveys and field applications. Second, our measure is experimentally-validated, as it predicts incentivized behavior in a controlled laboratory environment. ${ }^{1}$

Our paper is also related to concurrent work by Buser et al. (2019). They also developed an unincentivized survey question to measure the preference for competition using a representative sample of the population in the Netherlands. They show that their question (which asks participants: "How competitive do you consider yourself to be?") is associated with the same educational and career outcomes as an experimental measure of willingness to compete. We became aware of Buser et al. (2019)'s study only after we had designed our survey items and so we could not include their question in the battery of candidate questions that we tested in our experimental validation. Nevertheless, one of the questions we designed is coincidentally similar to the one used by Buser et al. (2019) — we ask participants whether the following statement

\footnotetext{
${ }^{1}$ An exception is the work of Bönte et al. (2017), who test the association between a psychometric scale designed to measure competitiveness and behavior in an incentivized experiment à la Niederle and Vesterlund (2007). They find a statistically significant correlation between the two.
} 
describes them: "I see myself as a competitive person"). Hence, we can indirectly test how our preferred question compares with theirs. With our sample, our question has greater predictive power than the alternative question. Although this result suggests it is better to use our question, it would nevertheless be important to compare directly the predictive power of the two independently-developed survey items, which is a task that we leave for further research.

The remainder of the paper is organized as follows. In Section 2, we describe our methodology to validate the survey questions using a laboratory experiment. In Section 3, we describe the validation exercise outside of the lab. Section 4 concludes.

\section{Experimental validation}

The main objective of our investigation is to identify a survey measure that captures the preference component of an individual's willingness to compete. We base our analysis on two sequential empirical strategies. The first strategy consists in finding, among a set of candidate survey items, the question that best correlates with having a preference for competition as identified in a laboratory environment. The second strategy probes the external validity of the first empirical analysis, by exploring whether the survey item that best explains preferences for competition in the laboratory can also explain the willingness of individuals to compete outside of the lab. In this section, we describe the design and results of the experimental validation of the survey questions, which constitutes our first strategy. We describe our strategy to examine the external validity of results in the next section.

\subsection{Design and procedures}

We conducted the experimental validation of the survey items in two steps. First, we elicited the participants' responses to a set of survey questions. Second, we had participants take part in a laboratory experiment designed to observe their competitive behavior and measure the extent to which it is due to a preference for competition.

We recruited 96 students from the University of Luxembourg through ORSEE (Greiner, 2015) to participate in a survey and a laboratory experiment at LISER-LAB. Participants were invited to sign up for a laboratory session 14 days in advance. Immediately after registering, they received an invitation to take part in an online survey containing 38 questions. Among these questions, we included eight questions related to competition. The remaining questions consisted of standard questionnaires used to measure personality traits, general values towards society, and demographic characteristics. We used a broad set of questions to avoid alerting participants that we are particularly interested in preferences for competition and thus limit any spillovers from the survey to the experiment. We provide the complete survey in Appendix A. 
Table 1. Candidate survey questions.

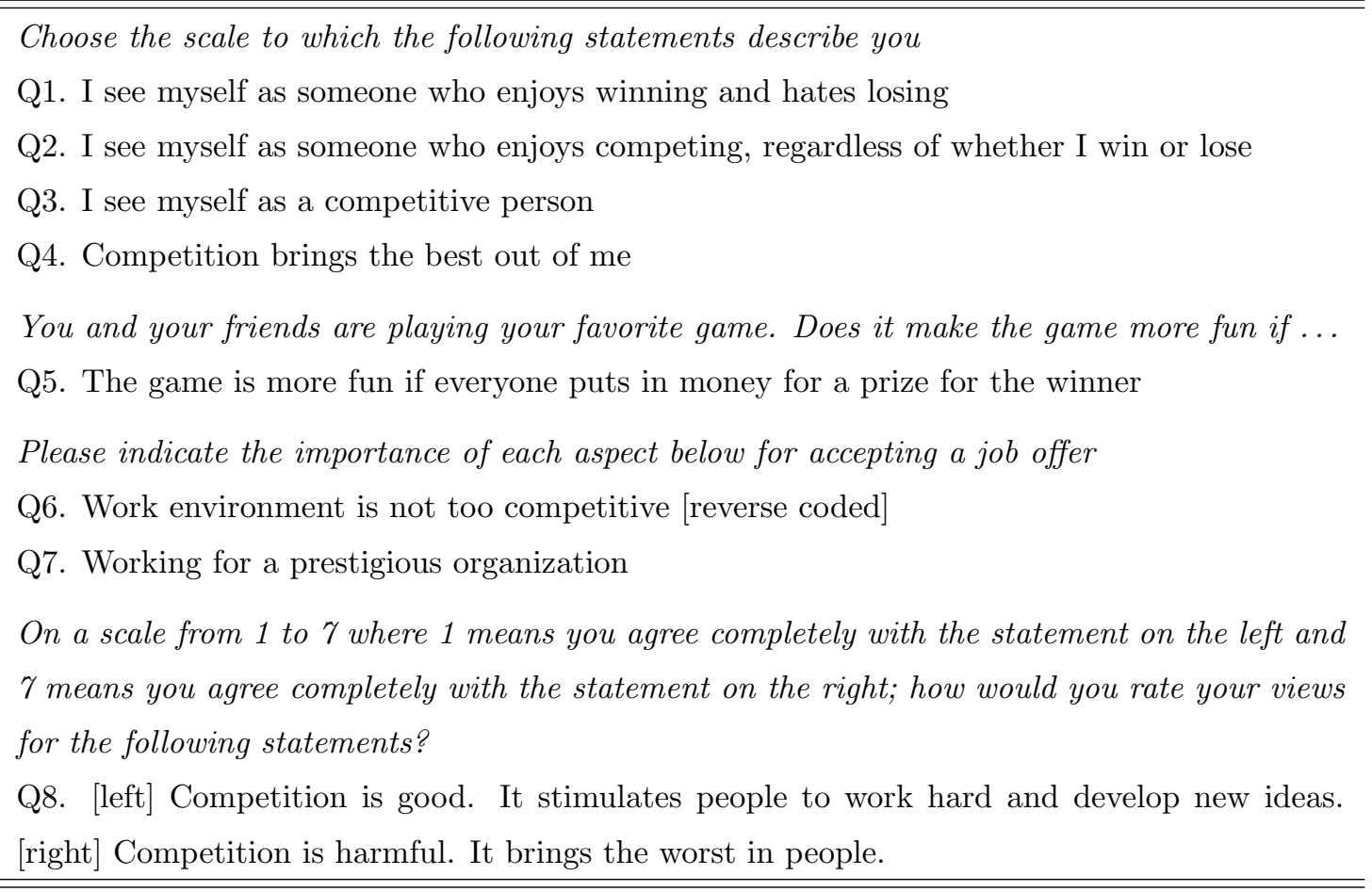

We report the eight competition questions in Table 1. We composed the first four questions with a preference for competition in mind. Questions Q1 to Q4 were integrated into a fifteenitem questionnaire measuring the big five personality traits (Lang et al., 2011). ${ }^{2}$ The next three questions were designed to be more indirect. Question Q5 was part of a three-item questionnaire while Q6 and Q7 were part of a five-item questionnaire. Finally, we took question Q8 from the widely-used World Values Survey (Inglehart et al., 2014). All questions used a 7-point Likert scale.

To further minimize spillovers between the survey and the experiment, participants had to complete the survey at least ten days before participating in the laboratory session. Of all participants who were invited, 90 (94\%) completed the survey in the specified period.

Participants then took part in a laboratory experiment designed to measure preferences for competition (Niederle and Vesterlund, 2007). The experiment was computerized and programmed in z-tree (Fischbacher, 2007). We informed them that the experiment consisted of five parts, one of which would be randomly chosen for payment at the end of the experiment. Participants read the instructions for each part before the start of the respective part. Importantly, participants did not receive any information about the performance or choices of others until the end of experiment. We provide the instructions and screenshots of the experiment in Appendix B.

\footnotetext{
${ }^{2}$ In all questionnaires with multiple items, the order of the items was randomized to avoid order effects.
} 
In parts one, two, and four, participants performed a real-effort task for four minutes. ${ }^{3}$ The task consisted of finding the two highest numbers two $4 \times 4$ matrices and add them up (for more details see, Weber and Schram, 2017). In part one, participants performed the real-effort task for which they received a piece-rate payment of $€ 1.00$ per correct answer. In part two, participants were assigned to groups of five and competed in a tournament that paid $€ 4.40$ per correct answer if they had the highest number of correct answers in their group (ties were broken randomly) and earned $€ 0$ otherwise. In part three, we elicit the participants' belief about their relative performance by asking them to tell us their expected probability of being the tournament winner in part two. We incentivized their response using the scoring rule proposed by Wilson and Vespa (2018), which is robust to varying degrees of risk aversion.

We observe the participants' willingness to compete in part four. In this part, we informed participants that they would perform the real-effort task once again and asked them to choose how they want to be paid. We follow Saccardo et al. (2018) and allow participants to choose a combination of piece-rate pay and tournament pay. Specifically, participants would choose $x \in[0,1]$ knowing that their payment per correct sum is given by $(1-x) \pi^{P}+x I^{W} \pi^{T}$, where $\pi^{P}$ is the piece-rate of $€ 1.00, \pi^{T}$ is the tournament-rate of $€ 4.40$, and $I^{W}$ is an indicator function that equals one if the participant is the tournament winner in part four and zero otherwise. To determine the tournament winners in part four, the performance of participants was compared to the performance of their group members in part two. The advantage of having participants compete against the past performance of others is that their payment-scheme choice ought to be unaffected by their expectations concerning the payment-scheme choice of others. We chose to record the participants' willingness to compete as a continuous measure instead of a binary choice between piece-rate and tournament (as in the original design of Niederle and Vesterlund, 2007) because it gives us a more precise individual measure of the intensity of the participants' preferences for competition (for a discussion on the merits of this procedure see Saccardo et al., 2018).

Finally, in part five, we measure the participants' risk preferences. To do so, we used a procedure mirroring their choice between piece-rate and tournament pay. Specifically, we gave participants six choices. In each choice, participants chose an $x \in[0,1]$ knowing that their payment is given by $(1-x) \pi^{C}+x I^{p} \pi^{R}$, where $\pi^{C}$ is a certain payment equal to $€ 1.00$ multiplied by their number of correct answers in part two, $\pi^{R}$ is a risky payment of $€ R$ multiplied by their number of correct answers in part two, and $I^{p}$ is an indicator function that equals one with probably $p$ and zero otherwise. Across their six choices, we varied the value of $R$ between 2.75 and 11.00 and the probability $p$ between 0.10 and $0.55 .^{4}$

\footnotetext{
${ }^{3}$ In addition, before part one, the participants performed the real-effort task for one minute as an unpaid trial run.

${ }^{4}$ The precise combinations of $R$ and $p$ were: $(4.40,0.25),(2.75,0.40),(11.00,0.10),(4.84,0.25),(9.68,0.55)$, and
} 
In Appendix C, we report summary statistics of the participants' answers to the survey questions as well as their behavior and beliefs in the experiment (see Table C1). Also, in Table $\mathrm{C} 2$, we report the Pearson correlation coefficients between the survey questions.

\subsection{Results}

The first part of the analysis consists of identifying the survey question, among the eight we have, that can best explain participants' preference to perform in a competitive environment (the tournament). To do so, we follow a two-step procedure.

In a first step, as Niederle and Vesterlund (2007) and Buser et al. (2014), we interpret the participants' payment-scheme choice as their preference for competition once we control for other reasons they may have for choosing tournament pay. Specifically, we run an OLS regression with the fraction of their payment participants assign to the tournament payment scheme as the dependent variable. As independent variables, we use the participants' individual ability in the task (measured by their performance in parts one, two, and four), their risk attitude (their six choices in part five), and their belief about the likelihood of winning a tournament (elicited in part three). The residuals obtained from this initial regression represent the "unexplained" preference component of the participants' competitive behavior, their so-called preference for competition.

The second step consists of estimating the predictive power of our eight survey questions to explain this preference. More specifically, we run eight separate OLS regressions with the firststep regression residuals as dependent variable and each of the survey questions as independent variable. In order to make the coefficients easy to interpret, we standardized both the dependent and the independent variables to have a mean of zero and a standard deviation of one. In Table 2 , we report the estimated coefficient of each regression along with its standard error and $p$ value, and the regression's R-squared as an estimate of goodness-of-fit.

The best fit is given by question Q4, which asks the degree to which participants think the following statement describes them: "Competition brings the best out of me". An increase of one standard deviation in the answer of this survey question is associated with an increase of 0.25 standard deviations in the participants' preference for competition.

To check the robustness of this result, we performed a couple of additional exercises. First, we checked whether aggregating survey questions into a common competition scale gives us a better predictor of the participants' behavior. To perform this check, we used principal component analysis to create a common factor from the survey questions and then regressed the participants' preference for competition on this common factor. ${ }^{5}$ The resulting coefficient is

$(5.28,0.25)$.

${ }^{5}$ We used questions Q2 through Q8 to create the common factor because Q1 displays a negative association with the participants' preference for competition. Including Q1 gives the common factor a worse fit. 
Table 2. Predicting the participants' preference for competition with the survey questions

Note: OLS regressions with robust standard errors. In all cases, the dependent variable is the participants' preference for competition, which corresponds to the residuals of an initial regression of the fraction of compensation allocated to the tournament in part four of the experiment on the participants' performance, beliefs, and risk preferences.

\begin{tabular}{crccc}
\hline \hline Question & Coefficient & Std. err. & $\boldsymbol{p}$-value & R-squared \\
\hline Q1 & -0.135 & 0.121 & 0.268 & 0.018 \\
Q2 & 0.182 & 0.108 & 0.095 & 0.033 \\
Q3 & 0.100 & 0.102 & 0.329 & 0.010 \\
Q4 & 0.248 & 0.092 & 0.008 & 0.062 \\
Q5 & 0.083 & 0.103 & 0.422 & 0.007 \\
Q6 & 0.107 & 0.114 & 0.350 & 0.011 \\
Q7 & 0.101 & 0.108 & 0.352 & 0.010 \\
Q8 & 0.226 & 0.097 & 0.022 & 0.051 \\
\hline \hline
\end{tabular}

0.233 with a standard error of $0.104(p=0.027)$. Given that the coefficient of the common factor is of similar magnitude and statistical significance as the coefficient of question Q4, this analysis suggests that there is not much to gain in terms of additional explanatory power from taking into account the other survey questions. Second, we checked whether it is worth considering two questions instead of just one. To do this, we regressed the participants' preference for competition on combinations of two survey questions. ${ }^{6}$ The two-question regression with the best fit corresponds to the regression with questions Q4 and Q8. However, since the coefficient for Q8 in the two-question regression is smaller than that of Q4 and is statistically not different from zero $(\beta=0.168, p=0.119)$, we conclude that including a second question does not add significant explanatory power.

Result 1 The question "Competition brings the best out of me" has the highest explanatory power for the preference for competition.

\section{Predicting competitive behavior in the field}

With the first part of the analysis, we have identified the survey question that best explains the desire to perform in a competitive environment inside the laboratory. A natural follow-up question is whether this survey question can also explain competitive behavior outside the laboratory. To answer this question, we surveyed a group of individuals that previous research has identified as being especially competitive, namely, professional athletes (Barron et al., 2000). If our survey question is capturing a preference for competition, then it should classify professional athletes as more competitive than non-athletes.

\footnotetext{
${ }^{6}$ Once again, we restricted this analysis to questions Q2 through Q8 because Q1 shows a negative relationship with preferences for competition.
} 
Table 3. Preferences for competition among professional athletes and non-athletes

Note: Summary statistics of the answer to question Q4, which asks the degree to which individuals think the following statement describes them: "Competition brings the best out of me". Answers were provided in a 10 -point Likert scale.

\begin{tabular}{lcc}
\hline \hline & Athletes & Non-athletes \\
\hline Mean & 8.100 & 5.731 \\
Standard deviation & 1.861 & 2.795 \\
\# observations & 90 & 78 \\
\cline { 2 - 3 } & \multicolumn{2}{c}{ MEN } \\
\cline { 2 - 3 } Mean & 8.197 & 6.472 \\
Standard deviation & 1.691 & 2.501 \\
\# observations & 61 & 36 \\
\cline { 2 - 3 } & \multicolumn{2}{c}{ WOMEN } \\
\cline { 2 - 3 } Mean & 7.897 & 5.095 \\
Standard deviation & 2.193 & 2.903 \\
\# observations & 29 & 42 \\
\hline \hline
\end{tabular}

\subsection{Design and procedures}

We asked our survey question (Q4) to 90 young professional athletes who were recruited to participate in an experiment at LISER-LAB. The athletes are all from Luxembourg and practice a variety sports, the most common being cycling (20\%), swimming (15\%), judo (13\%) and gymnastics (12\%). As a control group, we also asked our survey question to 78 students of the University of Luxembourg who are of similar age as the professional athletes (between 18 and 30 years old) and who were recruited to participate in the same experiment. ${ }^{7}$ Participants completed a survey asking them the type of sport they practiced and our question Q4. ${ }^{8}$

\subsection{Results}

In Table 3, we show the summary statistics of the answer to the survey question comparing professional athletes and non-athletes. On average, the answer to our survey question measuring preferences for competition are clearly lower for non-athletes (5.731 out of 10) than for athletes (8.100 out of 10). An average athlete is 0.848 standard deviations more competitive than the average non-athlete. The large gap in preferences for competition between the two populations is also evident in Figure 1, which plots the cumulative distribution of the answer to Q4 for athletes and non-athletes. We can see that the median athlete is more competitive than $71 \%$

\footnotetext{
${ }^{7}$ The experiment was designed and conducted by a group of researchers at the University of Montpellier (Bravaccini et al., 2019), who kindly agreed to include our survey question in their post-experimental questionnaire.

${ }^{8}$ Since the experiment was conducted in French, the question was translated to match the language of the experiment. Moreover, in order to use the same scale as other unrelated questions present in the questionnaire, the answers to our question were recorded using an 11-point Likert scale ranging from 0 to 10.
} 


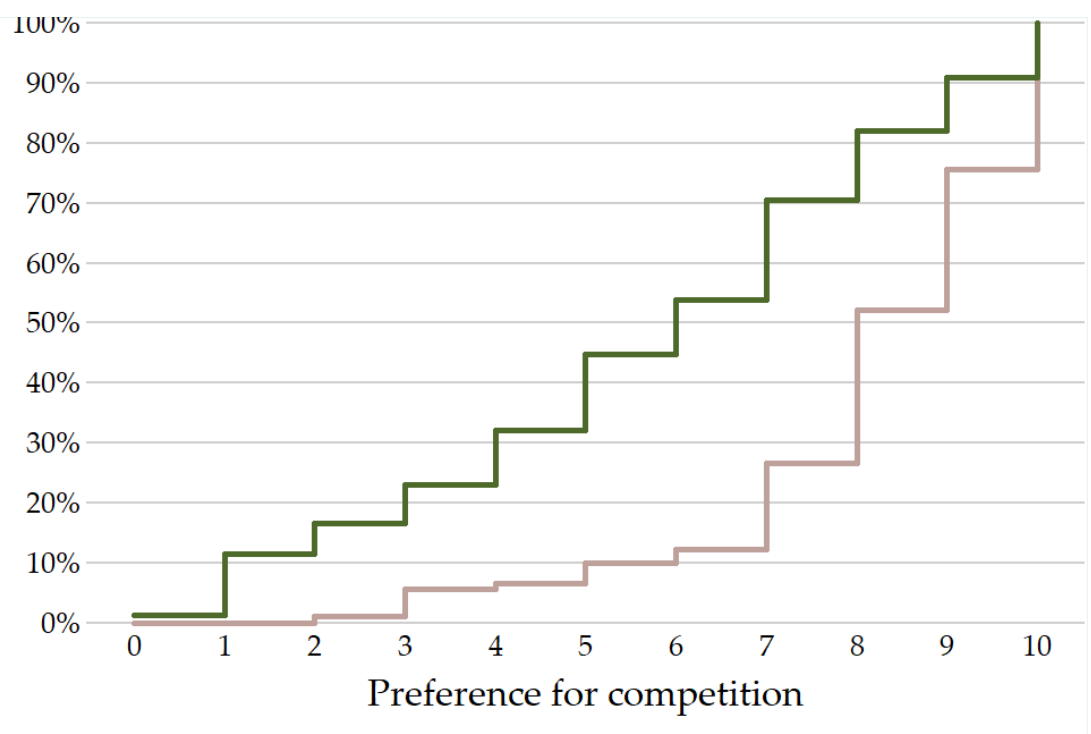

Preference for competition

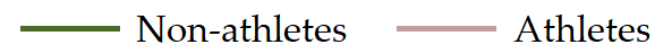

Figure 1. Cumulative distributions of the preference for competition

Note: Cumulative distributions for athletes and non-athletes of the answer to question Q4, which asks the degree to which individuals think the following statement describes them: "Competition brings the best out of me". Answers were provided in a 10-point Likert scale.

of the non-athletes. The two distributions are significantly different (Mann-Whitney U test, $p<0.001)$.

As a robustness check, we did the comparison between athletes and non-athletes separately by gender. Since men have been found to be more competitive than women in many student populations (for a review, see Dariel et al., 2017), the difference in preferences for competition reported above could be driven by differences in the fraction of men and women in the two populations ( $32 \%$ of the athletes are women while $54 \%$ of the non-athletes are women). In the lower part of Table 3, we show the summary statistics of the answer to Q4 for men and women. We find that both male and female athletes are significantly more competitive than their non-athlete counterparts (Mann-Whitney U tests, $p<0.001$ for both). ${ }^{9}$

Result 2 The question "Competition brings the best out of me" captures differences in competitiveness between professional athletes and others.

\section{Discussion}

We validated a self-reported measure of preference for competition using the validation methodology introduced by Falk et al. (2016). To do so, we compared the explanatory power of eight

\footnotetext{
${ }^{9}$ In line with previous literature, we find a significant difference in preferences for competition between men and women among non-athlete students (Mann-Whitney U test, $p=0.031$ ). Moreover, consistent with there being a strong positive selection for competitive individuals to become a professional athlete, we do not find that male athletes are significantly more competitive than female athletes (Mann-Whitney $\mathrm{U}$ test, $p=0.727$ ).
} 
candidate questions in predicting individuals' preference for competition as measured by people's behavior in the laboratory Niederle and Vesterlund (2007). We then further explored the validity of the best survey question by testing whether it predicts competitive behavior in the field: namely, whether an individual is a professional athlete. The question captures differences between professional athletes and non-athletes, confirming its reliable predictive power. Based on this evidence, we suggest the use of this tool to measure individual's preference for competition in large-scale surveys.

\section{References}

Barron, J. M., Ewing, B. T., and Waddell, G. R. (2000). The effects of high school athletic participation on education and labor market outcomes. Review of Economics and Statistics, 82(3):409-421.

Berge, L. I. O., Bjorvatn, K., Garcia Pires, A. J., and Tungodden, B. (2015). Competitive in the lab, successful in the field? Journal of Economic Behavior \& Organization, 118:303-317.

Bönte, W., Lombardo, S., and Urbig, D. (2017). Economics meets psychology: Experimental and selfreported measures of individual competitiveness. Personality and Individual Differences, 116:179-185.

Bravaccini, S., Dubois, D., and Willinger, M. (2019). Competitive spirits: do athletes have a taste for competition? Personal communication on 9/12/2019.

Buser, T., Niederle, M., and Oosterbeek, H. (2014). Gender, competitiveness, and career choices. The Quarterly Journal of Economics, 129(3):1409-1447.

Buser, T., Niederle, M., and Oosterbeek, H. (2019). Can competitiveness predict education and labor market outcomes? evidence from incentivized choices and validated survey measures. IMEBESS 2019 conference presentation.

Buser, T., Peter, N., and Wolter, S. C. (2017a). Gender, competitiveness, and study choices in high school: Evidence from switzerland. American Economic Review, 107(5):125-130.

Buser, T., Peter, N., and Wolter, S. C. (2017b). Gender, willingness to compete and career choices along the whole ability distribution. IZA Discussion Paper No. 10976.

Dariel, A., Kephart, C., Nikiforakis, N., and Zenker, C. (2017). Emirati women do not shy away from competition: evidence from a patriarchal society in transition. Journal of the Economic Science Association, 3(2):121-136.

Dohmen, T., Falk, A., Huffman, D., Sunde, U., Schupp, J., and Wagner, G. G. (2011). Individual risk attitudes: Measurement, determinants, and behavioral consequences. Journal of the European Economic Association, 9(3):522-550.

Erkut, H. and Reuben, E. (2019). Preference measurement and manipulation in experimental economics. In Schram, A. and Ule, A., editors, Handbook of Research Methods and Applications in Experimental Economics, chapter 3, pages 39-56. Edward Elgar Publishing, Glos, UK.

Falk, A., Becker, A., Dohmen, T., Enke, B., Huffman, D., and Sunde, U. (2018). Global evidence on economic preferences. The Quarterly Journal of Economics, 133(4):1645-1692.

Falk, A., Becker, A., Dohmen, T. J., Huffman, D., and Sunde, U. (2016). The preference survey module: A validated instrument for measuring risk, time, and social preferences. IZA Discussion Paper 9674. 
Fischbacher, U. (2007). z-tree: Zurich toolbox for ready-made economic experiments. Experimental economics, 10(2):171-178.

Greiner, B. (2015). Subject pool recruitment procedures: organizing experiments with orsee. Journal of the Economic Science Association, 1(1):114-125.

Heckman, J. J., Jagelka, T., and Kautz, T. D. (2019). Some contributions of economics to the study of personality. Technical report, National Bureau of Economic Research.

Inglehart, R., Haerpfer, C., Moreno, A., Welzel, C., Kizilova, K., Diez-Medrano, J., Lagos, M., Norris, P., Ponarin, E., Puranen, B., et al. (2014). World values survey: All rounds-country-pooled datafile version. Madrid: JD Systems Institute. Retrieved August, 1:2018.

Kamas, L. and Preston, A. (2018). Competing with confidence: The ticket to labor market success for college-educated women. Journal of Economic Behavior $\&$ Organization, 155:231-252.

Lang, F. R., John, D., Lüdtke, O., Schupp, J., and Wagner, G. G. (2011). Short assessment of the big five: robust across survey methods except telephone interviewing. Behavior Research Methods, $43(2): 548-567$.

Newby, J. L. and Klein, R. G. (2014). Competitiveness reconceptualized: Psychometric development of the competitiveness orientation measure as a unified measure of trait competitiveness. The Psychological Record, 64(4):879-895.

Niederle, M. and Vesterlund, L. (2007). Do women shy away from competition? do men compete too much? The Quarterly Journal of Economics, 122(3):1067-1101.

Reuben, E., Sapienza, P., and Zingales, L. (2019). Taste for competition and the gender gap among young business professionals. Working paper, New York University Abu Dhabi.

Reuben, E., Wiswall, M., and Zafar, B. (2017). Preferences and biases in educational choices and labour market expectations: Shrinking the black box of gender. The Economic Journal, 127(604):2153-2186.

Roth, A. E. (1995). Introduction to experimental economics. In Kagel, J. H. and Roth, A. E., editors, The Handbook of Experimental Economics, chapter 1, pages 3-109. Princeton University Press, Princeton, NJ.

Saccardo, S., Pietrasz, A., and Gneezy, U. (2018). On the size of the gender difference in competitiveness. Management Science, 64(4):1541-1554.

Smither, R. D. and Houston, J. M. (1992). The nature of competitiveness: The development and validation of the competitiveness index. Educational and Psychological Measurement, 52(2):407-418.

Weber, M. and Schram, A. (2017). The non-equivalence of labour market taxes: A real-effort experiment. The Economic Journal, 127(604):2187-2215.

Wilson, A. and Vespa, E. (2018). Paired-uniform scoring: Implementing a binarized scoring rule with non-mathematical language. Working paper.

Zhang, Y. J. (2019). Culture, institutions and the gender gap in competitive inclination: Evidence from the communist experiment in China. The Economic Journal, 129(617):509-552. 


\section{Appendix A Survey questionnaire}

Below are the survey questions given to the participants before they participated in the experiment. Participants had to answer these questions at least ten days before the experiment took place. Within each set of questions, the order of the questions was randomized to avoid order effects.

Choose the scale to which the following statements describe you

\begin{tabular}{|c|c|c|c|c|c|c|c|}
\hline & $\begin{array}{r}1= \\
\text { Not at all } \\
\text { like me }\end{array}$ & 2 & 3 & 4 & 5 & 6 & $\begin{array}{l}7= \\
\text { Exactly } \\
\text { like me }\end{array}$ \\
\hline I see myself as someone who is reserved, quiet & O & O & $\bigcirc$ & O & O & O & O \\
\hline I see myself as someone who is talkative & O & O & $\bigcirc$ & $\bigcirc$ & O & 0 & 0 \\
\hline I see myself as someone who tends to be lazy & $\bigcirc$ & $\bigcirc$ & $\bigcirc$ & $\bigcirc$ & $\bigcirc$ & $\bigcirc$ & $\bigcirc$ \\
\hline I see myself as someone who is outgoing, sociable & O & $\bigcirc$ & $\bigcirc$ & $\bigcirc$ & $\bigcirc$ & $\bigcirc$ & 0 \\
\hline I see myself as someone who does a thorough job & $\bigcirc$ & $\bigcirc$ & $\bigcirc$ & 0 & O & $\bigcirc$ & $\bigcirc$ \\
\hline I see myself as a competitive person & $\bigcirc$ & $\bigcirc$ & $\bigcirc$ & $\bigcirc$ & $\bigcirc$ & $\bigcirc$ & $\bigcirc$ \\
\hline I see myself as someone who does things efficiently & $\bigcirc$ & $\bigcirc$ & $\bigcirc$ & $\bigcirc$ & $\bigcirc$ & $\bigcirc$ & $\bigcirc$ \\
\hline I see myself as someone who worries a lot & $\bigcirc$ & $\bigcirc$ & $\bigcirc$ & $\bigcirc$ & $\bigcirc$ & $\bigcirc$ & $\bigcirc$ \\
\hline I see myself as someone who gets nervous easily & $\bigcirc$ & $\bigcirc$ & $\bigcirc$ & $\bigcirc$ & $\bigcirc$ & O & $\bigcirc$ \\
\hline I see myself as someone who has a forgiving nature & $\bigcirc$ & $\bigcirc$ & $\bigcirc$ & $\bigcirc$ & $\bigcirc$ & $\bigcirc$ & $\bigcirc$ \\
\hline $\begin{array}{l}\text { I see myself as someone who has an active } \\
\text { imagination }\end{array}$ & $\bigcirc$ & $\bigcirc$ & $\bigcirc$ & $\bigcirc$ & $\bigcirc$ & 0 & 0 \\
\hline $\begin{array}{l}\text { I see myself as someone who is sometimes rude to } \\
\text { others }\end{array}$ & 0 & 0 & $\bigcirc$ & 0 & 0 & 0 & 0 \\
\hline $\begin{array}{l}\text { I see myself as someone who enjoys winning and } \\
\text { hates losing }\end{array}$ & 0 & 0 & $\bigcirc$ & 0 & 0 & 0 & 0 \\
\hline $\begin{array}{l}\text { I see myself as someone who is relaxed, handles } \\
\text { stress well }\end{array}$ & 0 & 0 & $\bigcirc$ & 0 & 0 & 0 & 0 \\
\hline $\begin{array}{l}\text { I see myself as someone who values artistic, } \\
\text { aesthetic experiences }\end{array}$ & $\bigcirc$ & 0 & 0 & 0 & 0 & 0 & 0 \\
\hline $\begin{array}{l}\text { I see myself as someone who is original, comes up } \\
\text { with new ideas }\end{array}$ & 0 & 0 & $\bigcirc$ & 0 & 0 & 0 & 0 \\
\hline $\begin{array}{l}\text { I see myself as someone who enjoys competing, } \\
\text { regardless of whether I win or lose }\end{array}$ & $\bigcirc$ & $\bigcirc$ & $\bigcirc$ & 0 & 0 & 0 & 0 \\
\hline $\begin{array}{l}\text { I see myself as someone who is considerate and kind } \\
\text { to almost everyone }\end{array}$ & $\bigcirc$ & 0 & 0 & 0 & 0 & 0 & 0 \\
\hline
\end{tabular}


You and your friends are playing your favorite game. Does it make the game more fun if...

\begin{tabular}{|c|c|c|c|c|c|c|c|}
\hline & $\begin{array}{r}1= \\
\text { Not at } \\
\text { all }\end{array}$ & 2 & 3 & 4 & 5 & 6 & $\begin{array}{l}7= \\
\text { Extremely } \\
\text { more fun }\end{array}$ \\
\hline ... everyone puts in money for a prize for the winner? & O & O & O & $\bigcirc$ & $\bigcirc$ & $\bigcirc$ & $\bigcirc$ \\
\hline ... a stranger joins? & O & O & O & $\bigcirc$ & $\bigcirc$ & $\bigcirc$ & $\bigcirc$ \\
\hline ... you play in teams rather than individually? & O & O & O & $\bigcirc$ & $\bigcirc$ & $\bigcirc$ & $\bigcirc$ \\
\hline
\end{tabular}

On a scale from 1 to 7 where 1 means you agree completely with the statement on the left and 7 means you agree completely with the statement on the right; how would you rate your views for the following statements?

\begin{tabular}{|c|c|c|c|c|c|c|c|c|}
\hline & 1 & 2 & 3 & 4 & 5 & 6 & 7 & \\
\hline $\begin{array}{l}\text { Competition is good. It } \\
\text { stimulates people to work hard } \\
\text { and develop new ideas }\end{array}$ & $\bigcirc$ & 0 & 0 & $\bigcirc$ & 0 & 0 & 0 & $\begin{array}{l}\text { Competition is harmful. It } \\
\text { brings the worst in people }\end{array}$ \\
\hline $\begin{array}{l}\text { Incomes should be made more } \\
\text { equal }\end{array}$ & 0 & 0 & 0 & $\bigcirc$ & 0 & 0 & 0 & $\begin{array}{l}\text { We need larger income } \\
\text { differences as incentives }\end{array}$ \\
\hline $\begin{array}{l}\text { In the long run, hard work } \\
\text { usually brings a better life }\end{array}$ & $\bigcirc$ & 0 & 0 & 0 & 0 & 0 & 0 & $\begin{array}{l}\text { Hard work doesn't generally } \\
\text { bring success, it's more a } \\
\text { matter of luck and connections }\end{array}$ \\
\hline $\begin{array}{l}\text { One should be cautious about } \\
\text { making major changes in life }\end{array}$ & 0 & 0 & 0 & 0 & 0 & 0 & 0 & $\begin{array}{l}\text { You will never achieve much } \\
\text { unless you act boldly }\end{array}$ \\
\hline
\end{tabular}

Please indicate the importance of each aspect below for accepting a job offer.

\begin{tabular}{|c|c|c|c|c|c|c|c|}
\hline & $\begin{array}{r}1=\text { Not } \\
\text { important } \\
\text { at all }\end{array}$ & 2 & 3 & 4 & 5 & 6 & $\begin{array}{l}7= \\
\text { Essential }\end{array}$ \\
\hline Good financial compensation & O & $\bigcirc$ & O & O & O & O & O \\
\hline Work environment is not too competitive & $\bigcirc$ & $\bigcirc$ & O & $\bigcirc$ & O & $\bigcirc$ & ○ \\
\hline The potential to contribute to society & $\bigcirc$ & $\bigcirc$ & $\bigcirc$ & $\bigcirc$ & $\bigcirc$ & $\bigcirc$ & $\bigcirc$ \\
\hline Work environment is not too competitive & $\bigcirc$ & $\bigcirc$ & $\bigcirc$ & $\bigcirc$ & $\bigcirc$ & $\bigcirc$ & $\bigcirc$ \\
\hline Job security and reasonable working hours & $\bigcirc$ & $\bigcirc$ & $\bigcirc$ & $\bigcirc$ & 0 & $\bigcirc$ & 0 \\
\hline
\end{tabular}


What is your age?

What is your nationality?

- Luxembourger

- German

- French

- Belgian

- Dutch

- Portuguese

- Other

What is your field of study?

- Computer Science

- Engineering

- Life Sciences

- Mathematics

- Physics

- Economics and Management

- Law

- Humanities

- Psychology

- Social Sciences and Education

- Teaching and Education

- Other

What is your biological gender?

- Male

- Female

Are you vegan / vegetarian?

- Male

- Female

Do you have siblings (including half/step/adoptive)?

- Yes

- No 
Please describe the birth order of siblings (including half/step/adoptive) in your family. In the case of twins, please select "twins" \& "sister" if the pair includes two female siblings but not you, "twins" \& "brother" if the pair includes two male siblings and not you, "twins" \& "brother" \& "sister" if the pair includes a sibling from each gender but not you, "twins" \& "me" \& "sister" if the pair includes you and a female sibling, and "twins" \& "me" \& "brother" if the pair includes you and a male sibling

\begin{tabular}{lcccc}
\hline & Me & Brother & Sister & Twins \\
\hline First child & $\square$ & $\square$ & $\square$ & $\square$ \\
Second child & $\square$ & $\square$ & $\square$ & $\square$ \\
Third child & $\square$ & $\square$ & $\square$ & $\square$ \\
Fourth child & $\square$ & $\square$ & $\square$ & $\square$ \\
Fifth child & $\square$ & $\square$ & $\square$ & $\square$ \\
\hline
\end{tabular}

\section{Appendix B Instructions}

Below are the screenshots of the experiment, which include all the instructions and control questions seen by the participants.

\section{Welcome}

In this study, you will be asked to complete five different tasks. They will take at most around twelve minutes each.

At the end of the study, you will receive $€ 10$ for your participation. In addition, we will randomly select one of the five tasks and pay you your earnings in that task. Hence, your total earnings at the end of the study will be your payment for the randomly-selected task plus $€ 10$. You will be paid your earnings in cash.

You will receive the instructions for each task right before you start the task. These instructions include a clear description of how your earnings for that task are calculated

Please do not communicate with other people while you are taking part in the study. If you have any questions, please raise your hand. We will come to your desk to answer your questions. All your information, decisions, and performance during this study are anonymous.

You will start with Task 1. Please read the instructions of Task 1 carefully. 
Task 1

In Task 1 you will be given $\mathbf{2 4 0}$ seconds to answer a series of math questions. You are not allowed to use any kind of calculator. When you start, you will see two matrices on the screen. Each matrix has 4 rows and 4 columns and is filled with randomly-generated numbers. Below is an example.

Your task is to find the highest number in each matrix and then sum the two numbers up. After submitting your answer, you will be able to see whether your answer was correct. Subsequently, irrespective of whether your answer was correct or incorrect, a new pair of matrices will appear.

Your earnings for Task 1 depend on your performance. Specifically, your earnings for Task 1 equal $€ 1.00$ per correct sum

Practice round: Before Task 1 starts, you will have a practice round of 60 seconds to familiarize yourself with the screen. Answers during the practice round do not count toward your earnings.

\begin{tabular}{|l|l|l|l|}
\hline 23 & 66 & 73 & 77 \\
\hline 48 & 31 & 74 & 29 \\
\hline 48 & 59 & 68 & 47 \\
\hline 78 & 32 & 50 & 52 \\
\hline
\end{tabular}

\begin{tabular}{|l|l|l|l|}
\hline 49 & 44 & 52 & 44 \\
\hline 49 & 64 & 62 & 53 \\
\hline 66 & 51 & 41 & 48 \\
\hline 82 & 53 & 52 & 23 \\
\hline
\end{tabular}

\section{Understanding check}

To ensure you correctly understood how the earnings for Task 1 are calculated, please answer the following question. Note that the numbers used in this question are not indicative of what constitutes good performance in this task.

1. Suppose you solved 10 sums correctly and 2 sums incorrectly. What are your earnings in Task 1 ? 

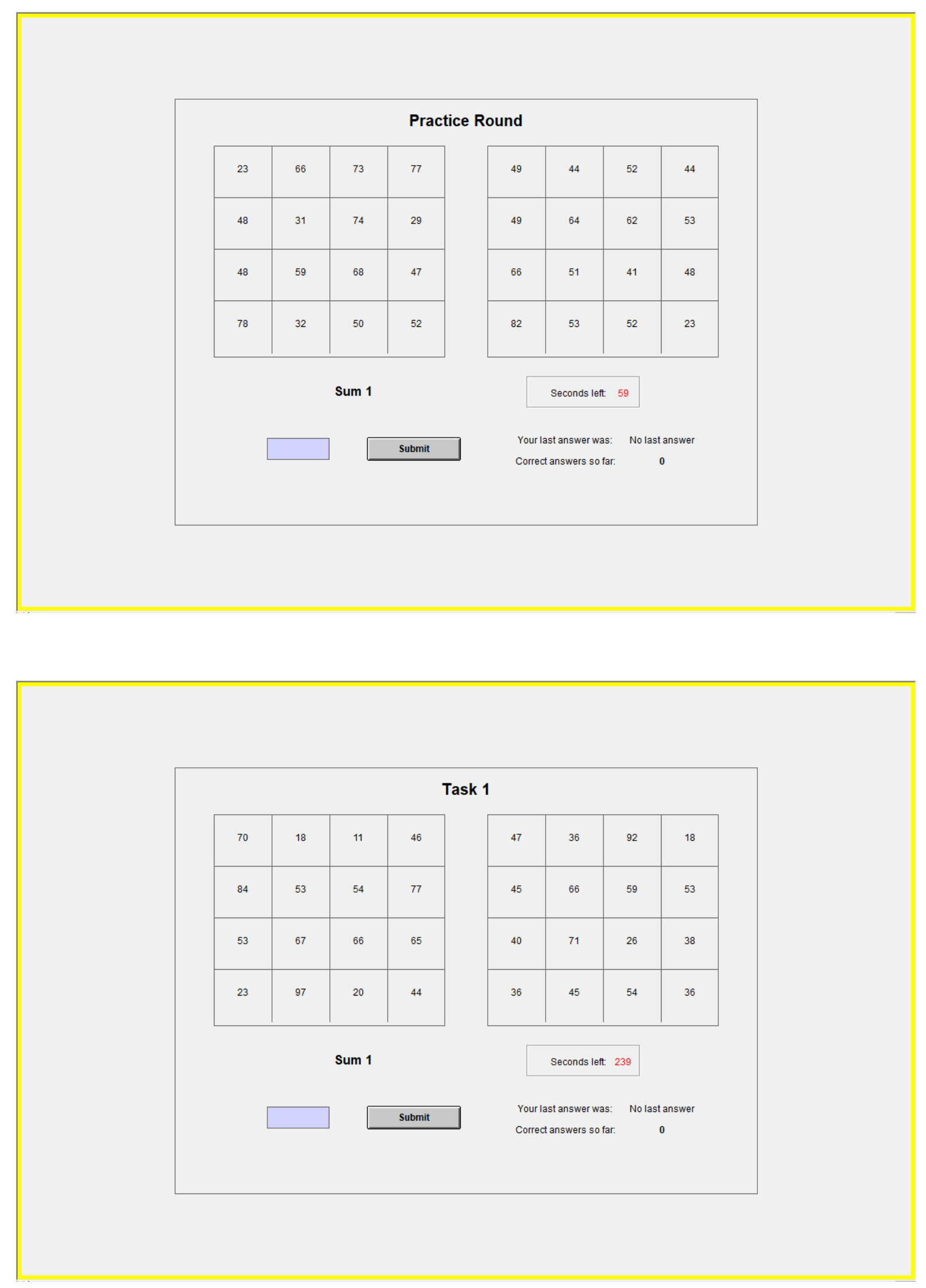


\section{Task 2}

As in Task 1, you will be given 240 seconds to calculate sums of the two highest numbers from pairs of matrices.

The difference with Task 1 is that, in Task 2, your earnings depend on your performance and the performance of three other participants. Specifically, you will be randomly assigned to a group of four participants. The individual who correctly solves the highest number of sums in the group will be the tournament winner. If there are ties, the tournament winner will be determined randomly among the tied group members.

The earnings for Task 2 are calculated as follows: the tournament winner receives $€ 4.40$ per correct sum while everyone else in the group receives $€ 0$. You will not be informed of how you did in the tournament until you have completed all five tasks.

\section{Understanding check}

To ensure you correctly understood how the earnings for Task 2 are calculated, please answer the following questions. Note that the numbers used in these questions are not indicative of what constitutes good performance in this task.

1. Suppose you solved 10 sums correctly and 2 sums incorrectly, and everybody else in your group solved less sums than you. What are your earnings in Task 2 ?

2. Suppose you solved 10 sums correctly and 2 sums incorrectly, and at least one person in your group solved more sums correctly than you. What are your earnings for Task 2? 


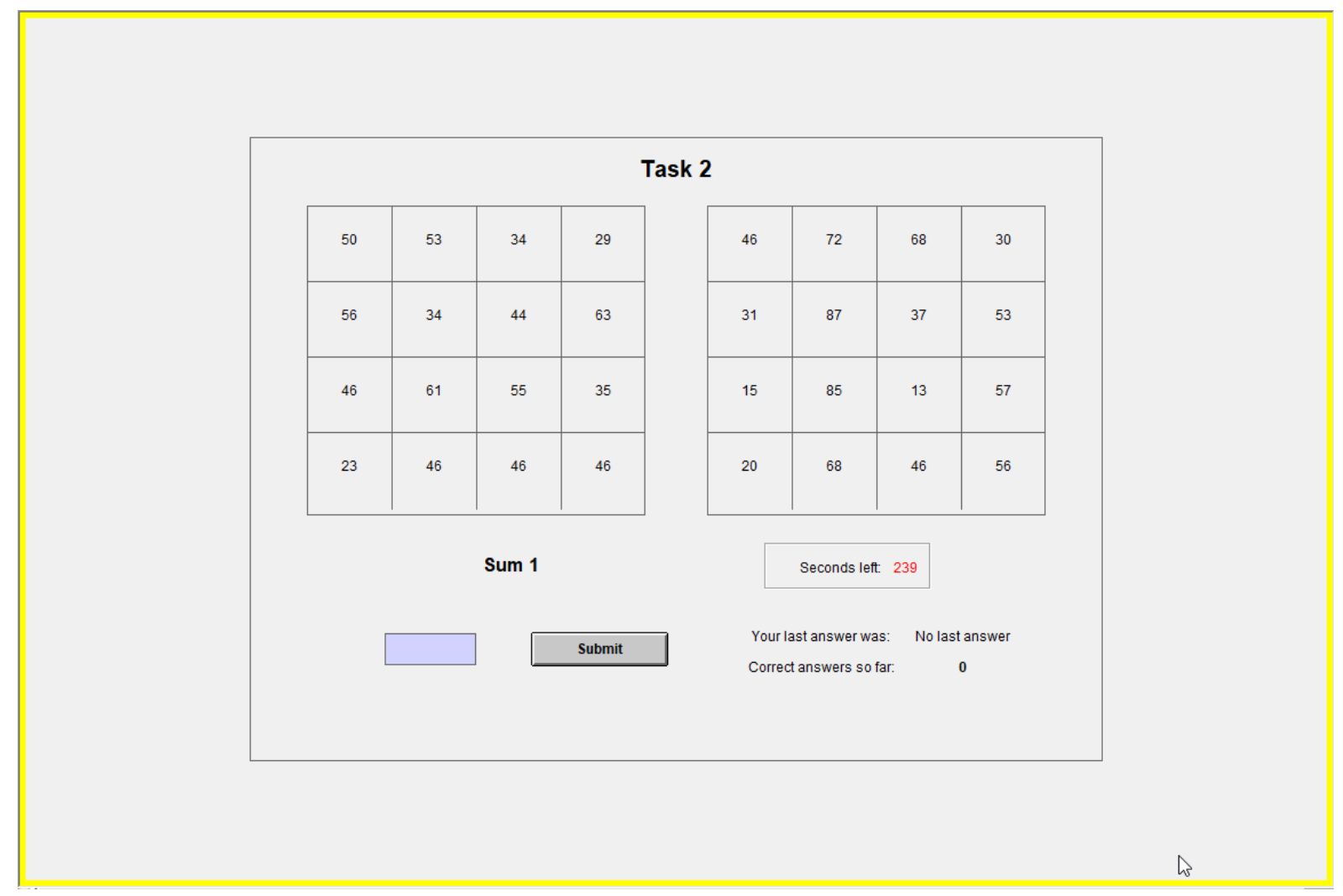

Task 3

In Task 3, you can earn money by answering the following question:

How likely do you think it is that you are the tournament winner in Task $2 ?$

Your answer can go from $0 \%$ (meaning you are completely certain that you are not the tournament winner) to $100 \%$ (meaning you are completely certain that you are the tournament winner). Your earnings in Task 3 can be either $€ 0$ or $€ 20$. The probability of earning $€ 20$ depends on two things 1. The actual outcome (whether you are the tournament winner or not)

2. The likelihood you selected as the answer to the question above.

The closer the likelihood you selected is to the actual outcome in Task 2, the higher the probability that you earn $€ 20$. In other words, if it turns out that you are the tournament winner in Task 2, then the probability that you earn $€ 20$ increases the closer your selected likelihood is to $100 \%$.

Conversely, if it turns out that you are not the tournament winner in Task 2 , then the probability that you earn $€ 20$ increases the closer your selected likelihood is to $0 \%$. 
You will select your likelihood of being the tournament winner picking a point on a line. You will be able to select any number between $0 \%$ and $100 \%$. We provide an example below to illustrate how the line will look (note that the number used in the example is not indicative of what constitutes a good or a bad answer in this task).

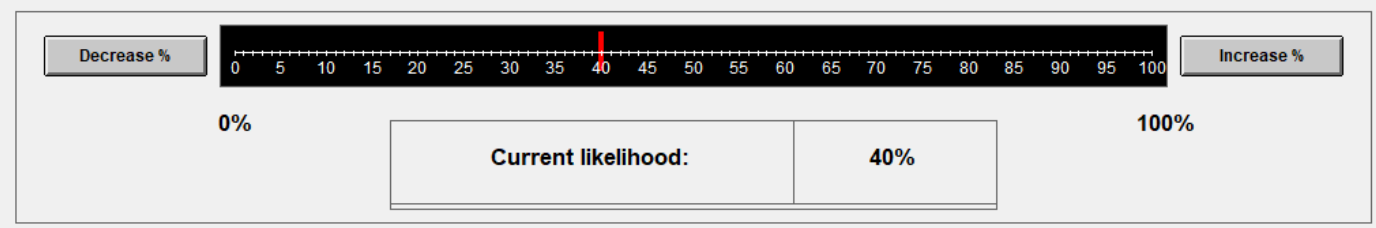

To help you to understand the consequences of your answer, you will see the following information below the line

[Example] Probability of earning $€ 20$

\begin{tabular}{|c|c|}
\hline $\begin{array}{c}\text { If you are the } \\
\text { WINNER }\end{array}$ & 0.640 \\
\hline $\begin{array}{c}\text { If you are NOT the } \\
\text { winner }\end{array}$ & 0.840 \\
\hline
\end{tabular}

On the left part of the screen, there is a table that shows the probability of earning $€ 20$ in the two possible outcomes: in case you are the tournament winner and in case you are not the tournament winner. As you can see in the example, if you select $40 \%$ on the line, the table on the left lets you know that your probability of earning $€ 20$ is 0.640 if you are the tournament winner and 0.840 if you are not the tournament winner.

On the right part of the screen, a graph shows the corresponding expected earnings for both outcomes. In the example, the bar graph on the right shows you the corresponding expected earnings: $€ 12.80$ if you are the tournament winner and $€ 16.80$ if you are not the tournament winner.

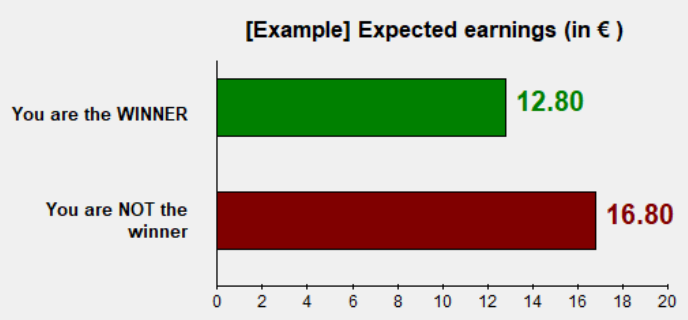

Go back

\section{Understanding check}

To ensure you correctly understood how the earnings for Task 3 are calculated, please answer the following questions. Note that the numbers used in these questions are not indicative of what constitutes a good answer in this task

Suppose that you think there is $15 \%$ chance that you are the tournament winner, and therefore, you use the slider to select $15 \%$ as your likelihood of being the tournament winner. According to the information in the table and graph below.
1. What is your probability of winning $€ 20$ if you turn out not to be the tournament winner?
2. What are your expected earnings if you turn out not to be the tournament winner?
3. What is your probability of winning $€ 20$ if you turn out to be the tournament winner?
4. What are your expected earnings if you turn out to be the tournament winner?
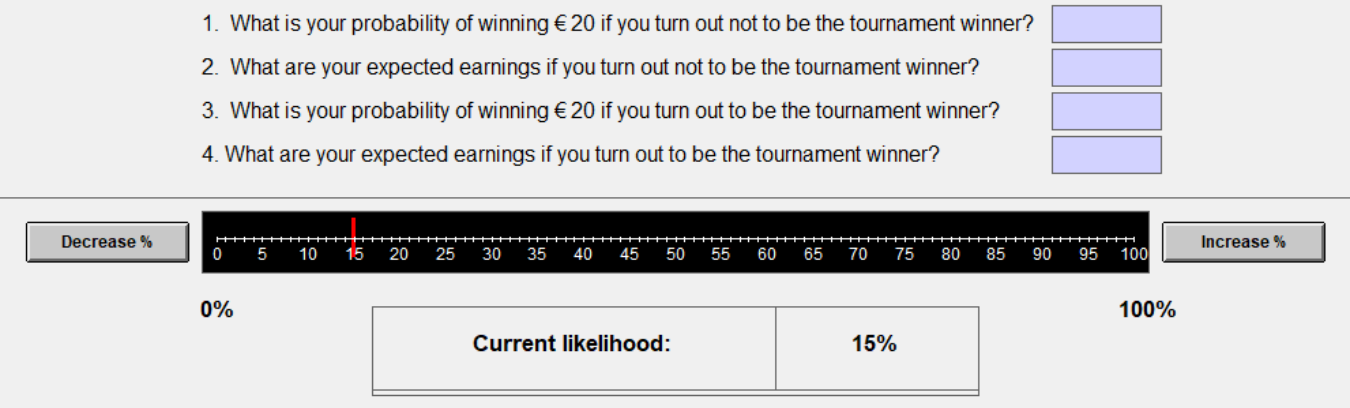

\section{Probability of earning $€ 20$}

\begin{tabular}{|c|c|}
\hline $\begin{array}{c}\text { If you are the } \\
\text { WINNER }\end{array}$ & 0.278 \\
\hline $\begin{array}{c}\text { If you are NOT the } \\
\text { winner }\end{array}$ & 0.978 \\
\hline
\end{tabular}

Go back
Expected earnings (in €)

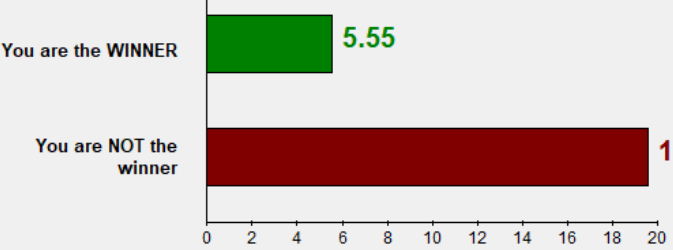


Task 3

How likely do you think it is that you are the tournament winner in Task 2?

$0 \%$

\begin{tabular}{|l|c|}
\hline Current likelihood: & $19 \%$ \\
\hline
\end{tabular}

Current likelihood:

$100 \%$

Given your current choice, the table shows the probability that you will earn $€ 20$ in each of the two possible outcomes.

The graph shows your corresponding expected earnings.

Probability of earning $€ 20$

Expected earnings (in €)

\begin{tabular}{|c|c|}
\hline $\begin{array}{c}\text { If you are the } \\
\text { WINNER }\end{array}$ & 0.344 \\
\hline $\begin{array}{c}\text { If you are NOT the } \\
\text { winner }\end{array}$ & 0.964 \\
\hline
\end{tabular}

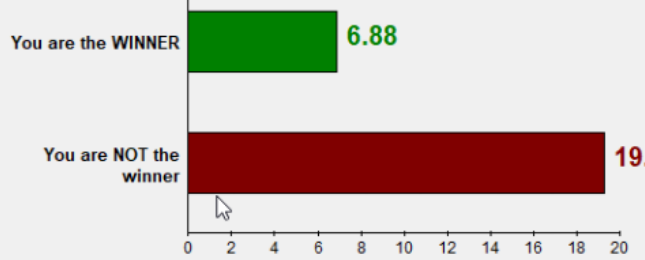

Task 4

As in Task 1 and 2, you will have once again 240 seconds to calculate sums of the two highest numbers from pairs of matrices. The difference between previous tasks and Task 4 is that you choose how you want to be paid for each correct sum in Task 4 . You choose a combination of an individual rate and a tournament rate by assigning euros to each rate. The two payments schemes are as follows:

- Individual rate: For each correct sum, the individual rate pays the amount of euros you assign to this rate. For example, if you assign $€ 1.00 \mathrm{t}$ the individual rate, then then you will receive $€ 1.00$ per correctly answered sum in Task 4 . Your earnings from the individual rate do not depend on the performance of other participants.

- Tournament rate: For each correct sum, the tournament rate pays the amount of euros you assign to this rate if you are the tournament winner in Task 4 . Specifically, your pe formance in Task 4 will be compard with the performance of the other members of your group in Task 2 . $Y$ determined among the tied group members. If you are not the tournament winner, then you earn $€ 0$

In summary, your earnings in Task 4 are:

-- If you are not the tournament winner in Task 4: (Individual rate) $\times$ (correct sums in Task 4)

- If you are the tournament winner in Task 4: (Individual rate + Tournament rate) $\times$ (correct sums in Task 4) 
To assign euros to the individual and tournament rates, you will pick a point on line like the one below.

Every point on the line corresponds to a combination of individual rate and tournament rate. Points closer to the left assign more euros to the individual rate and less euros to the tournament rate while points closer to the right assign more euros to the tournament rate and less euros to the individual rate.

To make a choice, use your mouse to click on a point on the line. Once you click, you will see the selected individual rate and tournament rate on the table below the line. You can adjust your choice by clicking a different point on the line or with the buttons labelled with the left and right arrows. To confirm your final assignment, click the 'Confirm' button on the bottom right part of your screen.

\begin{tabular}{|l|l|c|}
\hline \multirow{2}{*}{$\begin{array}{l}\text { Individual } \\
\text { rate }\end{array}$} & [Example] Current assignment \\
\hline & Individual rate & $€ 0.50$ \\
\hline & Tournament rate & $€ 2.22$ \\
\hline
\end{tabular}

We provide a few examples next. Note that the numbers used in these examples are for illustration purposes only and do not convey what a good or a bad choice is in this task

\section{Example 1}

Imagine you chose the point below. At this point, you have an individual rate of $€ 0.33$ per correct sum and a tournament rate of $€ 2.98$ per correct sum. This means that:

- - If you are not the tournament winner in Task 4 , you earn $€ 0.33$ per correct sum: $€ 0.33$ from your individual rate choice plus $€ 0$ from your tournament rate choice.

-- If you are the tournament winner in Task 4 , you earn $€ 3.31$ per correct sum: $€ 0.33$ from your individual rate choice plus $€ 2.98$ from your tournament rate choice.

\begin{tabular}{|l|l|c|}
\hline \multirow{2}{*}{$\begin{array}{l}\text { Individual } \\
\text { rate }\end{array}$} & [Example] Current assignment \\
\hline & Individual rate & $€ 0.33$ \\
\hline & Tournament rate & $€ 2.98$ \\
\hline
\end{tabular}




\section{Example 2}

Imagine you chose the point below. At this point, you have an individual rate of $€ 0.79$ per correct sum and a tournament rate of $€ 0.93$ per correct sum. This means that

-- If you are not the tournament winner in Task 4 , you earn $€ 0.79$ per correct sum: $€ 0.79$ from your individual rate choice plus $€ 0$ from your tournament rate choice.

-- If you are the tournament winner in Task 4 , you earn $€ 1.72$ per correct sum: $€ 0.79$ from your individual rate choice plus $€ 0.93$ from your tournament rate choice.

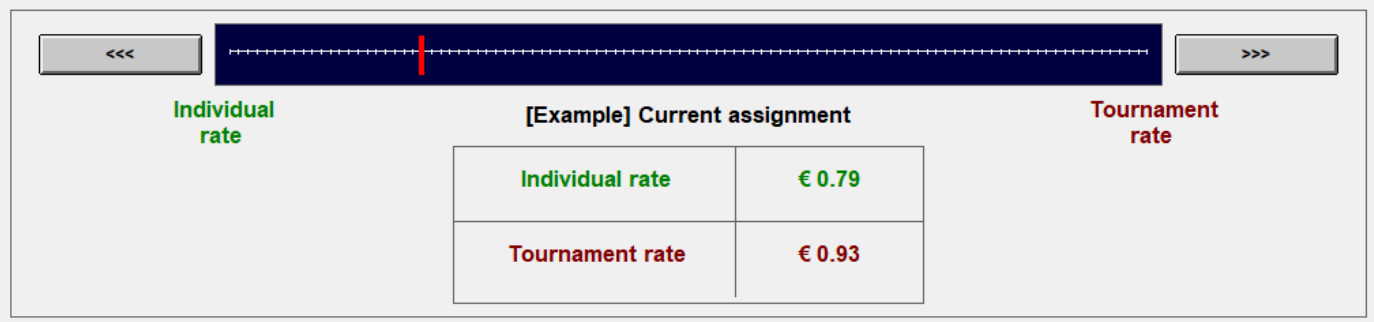

\section{Example 3}

Imagine you chose the point below. At this point, you have an individual rate of $€ 1.00$ per correct sum and a tournament rate of $€ 0.00$ per correct sum. This means that:

- - If you are not the tournament winner in Task 4 , you earn $€ 1.00$ per correct sum: $€ 1.00$ from your individual rate choice plus $€ 0$ from your

tournament rate choice.

- If you are the tournament winner in Task 4 , you earn $€ 1.00$ per correct sum: $€ 1.00$ from your individual rate choice plus $€ 0$ from your tournament rate choice.

\begin{tabular}{|l|l|c|}
\hline \multirow{2}{*}{$\begin{array}{c}\text { Individual } \\
\text { rate }\end{array}$} & \multicolumn{2}{|c|}{ [Example] Current assignment } \\
\hline & Individual rate & $€ 1.00$ \\
\hline & Tournament rate & $€ 0.00$ \\
\hline
\end{tabular}




\section{Understanding check}

To ensure you correctly understood how the earnings for Task 4 are calculated, please answer the following questions. Note that the numbers used in these questions are not indicative of what constitutes good performance in this task

1. For the tournament rate, your performance in Task 4 will be compared to:

$$
\begin{aligned}
& \sim \text { Your group members' past performance in Task } 2 \\
& \subset \text { Your group members' future performance in Task } 4 \\
& \subset \text { Your group members' average performance in Task } 1 \text { and Task } 2 \\
& \subset \text { Your own past performance in Task } 2
\end{aligned}
$$

2. Suppose you solved 10 sums correctly in Task 4 and everybody else in your group solved less than 10 additions correctly in Task 2 . What are your earnings for Task 4 if you assigned.
a) $€ 1.00$ to the individual rate and $€ 0.00$ to the tournament rate?
b) $€ 0.00$ to the individual rate and $€ 4.40$ to the tournament rate?
c) $€ 0.25$ to the individual rate and $€ 3.30$ to the tournament rate?
d) $€ 0.75$ to the individual rate and $€ 1.10$ to the tournament rate?

3. Suppose you solved 10 sums correctly in Task 4 and that at least one person in your group solved more than 10 sums correctly in Task 2 . What are your earnings for Task 4 if you assigned
a) $€ 1.00$ to the individual rate and $€ 0.00$ to the tournament rate?
b) $€ 0.00$ to the individual rate and $€ 4.40$ to the tournament rate?
c) $€ 0.25$ to the individual rate and $€ 3.30$ to the tournament rate?
d) $€ 0.75$ to the individual rate and $€ 1.10$ to the tournament rate? 
Task 4

Pick a point on the line to choose how you want to be paid for your performance in Task 4

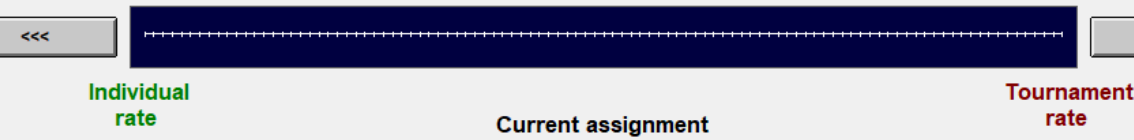

\begin{tabular}{|c|c|}
\hline Individual rate & Please choose \\
\hline Tournament rate & Please choose \\
\hline
\end{tabular}

\section{Task 5}

Task 5 consists of 6 rounds. Your earnings in this task correspond to your earnings in one randomly-selected round. In each round, you decide how you want to be paid by choosing a combination of a certain amount and an uncertain amount The two options are:

- Certain amount: You always earn the amount of money you assign to the certain amount

- Uncertain amount: You earn the amount of money you assign to the uncertain amount only with a given probability. For example, if the given probability is $50 \%$, then you earn the amount you assign to the uncertain amount half the time and earn $€ 0$ otherwise. You will be told the probability of winning the uncertain amount before you you earn the amo

In summary, your earnings in a round of Task 5 are:

- If you win the uncertain amount Certain amount + Uncertain amount

- If you do not win the uncertain amount. Certain amount

To assign euros to the certain and uncertain amounts, you will pick a point on line like the one below. Every point on the line corresponds to a combination of certain and uncertain amounts. Points closer to the left assign more euros to the certain amount and less euros to the uncertain amount while points closer to the right assign more euros to the uncertain amount and points to the certain amount. To make a choice, use your mouse to click on a point on the line. Once you click, you will see the selected certain and uncertain amount on the table below the line.

\begin{tabular}{|c|c|c|c|c|c|}
\hline$\ll$ & & +1 & 1,1, & $+1 .+1$ & $\gg$ \\
\hline & \multirow{3}{*}{$\begin{array}{l}\text { Zertain } \\
\text { mount }\end{array}$} & \multicolumn{2}{|c|}{ [Example] Current choice } & \multirow{3}{*}{$\begin{array}{l}\text { Uncer } \\
\text { amou }\end{array}$} & \\
\hline & & Certain amount & $€ 5.00$ & & \\
\hline & & $\begin{array}{c}\text { Uncertain amount } \\
\text { (with probability } 50 \% \text { ) }\end{array}$ & $€ 11.11$ & & \\
\hline
\end{tabular}


We provide one example below. Note that the numbers used in this example are for illustration purposes only and do not convey what a good or a bad choice is in this task.

\section{Example}

Imagine that the probability of winning the uncertain amount is $35 \%$ and you chose the point below. At this point, you have a certain amount of $€ 7.00$ and an uncertain amount of $€ 9.52$. This means that

If you win the - If you win the uncertain amount, which happens with a $35 \%$ probability, then you eam $€ 16.52 € 7.00$ from the certain amount plus $€ 9.52$ from
the uncertain amount.

- If you do not win the uncertain amount, which happens with a $65 \%$ probability, then you earn $€ 7.00: € 7.00$ from the certain amount plus $€ 0$ from the uncentan

\begin{tabular}{|c|c|c|c|c|c|}
\hline$\ll$ & \multicolumn{4}{|c|}{ 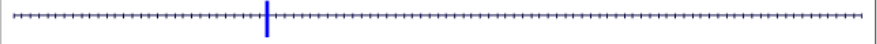 } & $\gg$ \\
\hline & \multirow{3}{*}{$\begin{array}{l}\text { Certain } \\
\text { amount }\end{array}$} & \multicolumn{2}{|c|}{ [Example] Current choice } & \multirow{3}{*}{\multicolumn{2}{|c|}{$\begin{array}{l}\text { Uncertain } \\
\text { amount }\end{array}$}} \\
\hline & & Certain amount & $€ 7.00$ & & \\
\hline & & $\begin{array}{l}\text { Uncertain amount } \\
\text { (with probability } 35 \% \text { ) }\end{array}$ & $€ 9.52$ & & \\
\hline
\end{tabular}

\section{Task 5}

Round 1 out of 6

The probability of winning the uncertain amount in this round is: $25 \%$

Pick a point on the line to choose how you want to be paid in this round $\ll$

(...........

$\gg \gg$

Certain amount

(max $€ 1.00)$

\section{Current choice} (max € 4.40)

\begin{tabular}{|c|c|}
\hline Certain amount & Please choose \\
\hline $\begin{array}{c}\text { Uncertain amount } \\
\text { (with probability 25\%) }\end{array}$ & Please choose \\
\hline
\end{tabular}



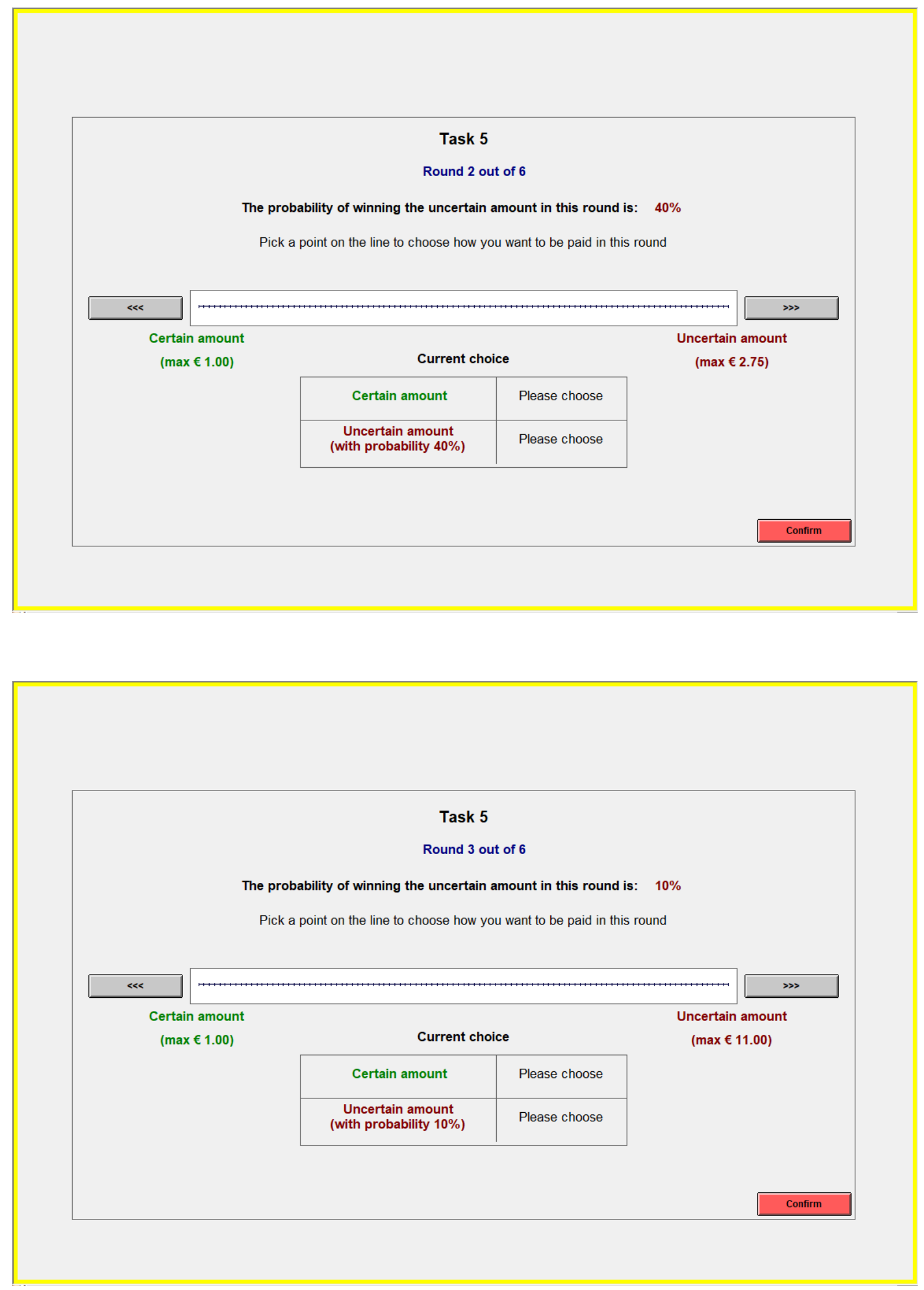


\section{Task 5}

Round 4 out of 6

The probability of winning the uncertain amount in this round is: $25 \%$

Pick a point on the line to choose how you want to be paid in this round

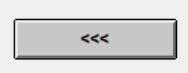

Certain amount

$(\max € 1.00)$

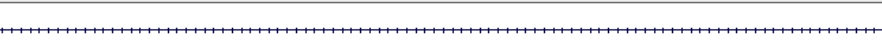

Uncertain amount

(max € 4.84)

\begin{tabular}{|c|c|}
\hline Certain amount & Please choose \\
\hline $\begin{array}{c}\text { Uncertain amount } \\
\text { (with probability 25\%) }\end{array}$ & Please choose \\
\hline
\end{tabular}

Task 5

Round 5 out of 6

The probability of winning the uncertain amount in this round is: $\mathbf{5 5 \%}$

Pick a point on the line to choose how you want to be paid in this round

$\ll$

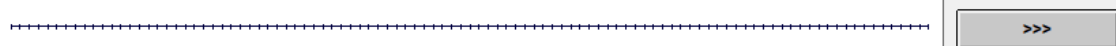

Certain amount

$(\max € 1.00)$

Current choice

Uncertain amount

(max $€ 2.00)$

\begin{tabular}{|c|c|}
\hline Certain amount & Please choose \\
\hline $\begin{array}{c}\text { Uncertain amount } \\
\text { (with probability 55\%) }\end{array}$ & Please choose \\
\hline
\end{tabular}




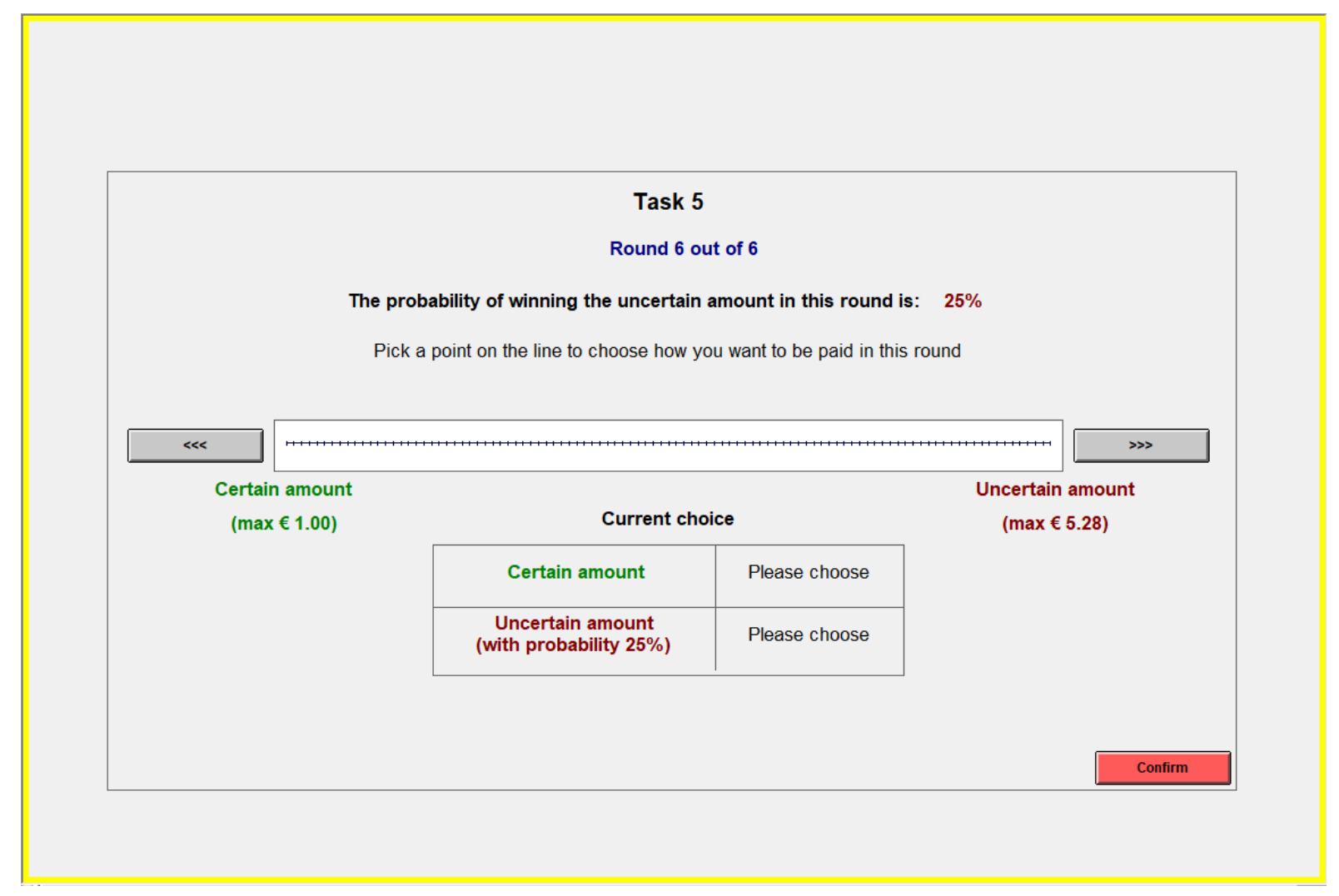

\section{Appendix C Descriptive statistics}

Table C1. Descriptive statistics of the survey questions and behavior in the experiment

Note: Descriptive statistics of the participants' behavior in the experiment (panel I), their demographic characteristics (panel II), and the eight survey questions designed to capture a preference for competition (panel III). Data corresponds to the 90 participants who participated in the survey and experiment.

\section{Experimental variables}

\begin{tabular}{lcc}
\hline \hline & Mean & Std. dev. \\
\hline Fraction assigned to tournament pay & 0.399 & 0.292 \\
Number of correct sums per try & 8.959 & 2.546 \\
Belief of winning the tournament & 0.513 & 0.265 \\
Fraction assigned to the uncertain amount & 0.390 & 0.239 \\
\hline \hline
\end{tabular}

II. Demographic variables

\begin{tabular}{lrc}
\hline \hline & Mean & Std. dev. \\
\hline Fraction of women & 0.567 & 1.562 \\
Age & 24.800 & 4.874 \\
\hline \hline
\end{tabular}

III. Survey questions

\begin{tabular}{ccc}
\hline \hline & Mean & Std. dev. \\
\hline Q1 & 4.256 & 1.562 \\
Q2 & 4.800 & 1.545 \\
Q3 & 4.544 & 1.470 \\
Q4 & 4.022 & 1.499 \\
Q5 & 3.378 & 1.911 \\
Q6 & 3.833 & 1.351 \\
Q7 & 4.211 & 1.590 \\
Q8 & 4.189 & 1.483 \\
\hline \hline
\end{tabular}


Table C2. Correlations between the survey questions

Note: Pairwise Pearson correlation coefficients between the eight survey questions designed to capture a preference for competition.

\begin{tabular}{lcccccccc}
\hline \hline & Q1 & Q2 & Q3 & Q4 & Q5 & Q6 & Q7 & Q8 \\
\hline Q1 & 1.0000 & & & & & & & \\
Q2 & 0.0307 & 1.0000 & & & & & & \\
Q3 & 0.1785 & 0.4394 & 1.0000 & & & & & \\
Q4 & 0.2039 & 0.3416 & 0.4228 & 1.0000 & & & & \\
Q5 & 0.1894 & 0.2199 & 0.1459 & 0.2323 & 1.0000 & & & \\
Q6 & -0.0382 & 0.2799 & 0.4139 & 0.1461 & 0.0856 & 1.0000 & & \\
Q7 & 0.1047 & 0.1089 & 0.1137 & 0.1159 & 0.1620 & -0.0253 & 1.0000 & \\
Q8 & 0.0953 & 0.4139 & 0.3337 & 0.2912 & 0.3312 & 0.2457 & 0.1973 & 1.000 \\
\hline \hline
\end{tabular}

